\title{
Article
}

\section{ERK-Directed Phosphorylation of mGlu5 Gates Methamphetamine Reward and Reinforcement in Mouse}

\author{
Elissa K. Fultz ${ }^{1}$, Sema G. Quadir ${ }^{1} \oplus$, Douglas Martin ${ }^{1}$, Daniel M. Flaherty ${ }^{1}$, Paul F. Worley ${ }^{2}$, Tod E. Kippin ${ }^{1,3,4} \mathbb{C}$ \\ and Karen K. Szumlinski $1,3, *$ (i) \\ 1 Department of Psychological and Brain Sciences, University of California Santa Barbara, \\ Santa Barbara, CA 93106, USA; elissa.fultz@gmail.com (E.K.F.); semaquadir@gmail.com (S.G.Q.); \\ douglas@martinhome.net (D.M.); dannyflare99@gmail.com (D.M.F.); kippin@ucsb.edu (T.E.K.) \\ 2 Department of Neuroscience, Johns Hopkins University School of Medicine, Baltimore, MD 21205, USA; \\ pworley1@jhmi.edu \\ 3 Department of Molecular, Cellular and Developmental Biology and the Neuroscience Research Institute, \\ University of California Santa Barbara, Santa Barbara, CA 93106, USA \\ 4 Institute for Collaborative Biotechnologies, University of California Santa Barbara, \\ Santa Barbara, CA 93106, USA \\ * Correspondence: szumlinski@ucsb.edu; Tel.: +1-805-893-2987; Fax: +1-805-893-4303
}

Citation: Fultz, E.K.; Quadir, S.G.; Martin, D.; Flaherty, D.M.; Worley, P.F.; Kippin, T.E.; Szumlinski, K.K. ERK-Directed Phosphorylation of mGlu5 Gates Methamphetamine Reward and Reinforcement in Mouse. Int. J. Mol. Sci. 2021, 22, 1473. https://doi.org/10.3390/ijms22031473

Received: 11 December 2020

Accepted: 28 January 2021

Published: 2 February 2021

Publisher's Note: MDPI stays neutral with regard to jurisdictional claims in published maps and institutional affiliations.

Copyright: (C) 2021 by the authors Licensee MDPI, Basel, Switzerland. This article is an open access article distributed under the terms and conditions of the Creative Commons Attribution (CC BY) license (https:/ / creativecommons.org/licenses/by/ $4.0 /)$.

\begin{abstract}
Methamphetamine (MA) is a highly addictive psychomotor stimulant drug. In recent years, MA use has increased exponentially on a global scale, with the number of MA-involved deaths reaching epidemic proportions. There is no approved pharmacotherapy for treating MA use disorder, and we know relatively little regarding the neurobiological determinants of vulnerability to this disease. Extracellular signal-regulated kinase (ERK) is an important signaling molecule implicated in the long-lasting neuroadaptations purported to underlie the development of substance use disorders, but the role for this kinase in the propensity to develop addiction, particularly MA use disorder, is uncharacterized. In a previous MA-induced place-conditioning study of C57BL/6J mice, we characterized mice as MA-preferring, -neutral, or -avoiding and collected tissue from the medial prefrontal cortex (mPFC). Using immunoblotting, we determined that elevated phosphorylated ERK expression within the medial prefrontal cortex (mPFC) is a biochemical correlate of the affective valence of MA in a population of C57BL/6J mice. We confirmed the functional relevance for mPFC ERK activation for MA-induced place-preference via site-directed infusion of the MEK inhibitor U0126. By contrast, ERK inhibition did not have any effect upon MA-induced locomotion or its sensitization upon repeated MA treatment. Through studies of transgenic mice with alanine point mutations on T1123/S1126 of mGlu5 that disrupt ERK-dependent phosphorylation of the receptor, we discovered that ERK-dependent mGlu5 phosphorylation normally suppresses MA-induced conditioned place-preference (MA-CPP), but is necessary for this drug's reinforcing properties. If relevant to humans, the present results implicate individual differences in the capacity of MA-associated cues/contexts to hyper-activate ERK signaling within mPFC in MA Use Disorder vulnerability and pose mGlu5 as one ERK-directed target contributing to the propensity to seek out and take MA.
\end{abstract}

Keywords: metabotropic glutamate receptor 5; place-conditioning; reinforcement; self-administration; vulnerability; methamphetamine; addiction

\section{Introduction}

In the wake of the opioid epidemic, the world is currently facing a psychostimulant crisis. The Drug Enforcement Agency of the United States reports a recent, major surge in the amount of methamphetamine (MA) seized by law enforcement, with a 15-fold higher supply and demand for psychostimulants than opioids world-wide [1]. By 2017, the total number of U.S. persons reporting past year stimulant use is higher than that for opioids [1], with a similar trend observed in other countries, particularly in Asia [1,2]. Accordingly, 
the Center for Disease Control of the United States and the World Health Organization report that deaths involving MA have risen rapidly to reach epidemic proportions [1,2]. However, unlike Opioid Use Disorder, no clinically approved pharmacotherapy exists for treating Methamphetamine Use Disorder.

MA is an indirect dopamine agonist [3,4] and profoundly increases DA concentrations within forebrain terminals, in particular the nucleus accumbens, dorsal striatum, and prefrontal cortex (PFC) [5]. Indeed, the bulk of neurobiological research regarding Methamphetamine Use Disorder in humans has focused upon forebrain dopamine systems, e.g., [6-9], with a good majority of the extant basic science studies in rodent models of Methamphetamine Use Disorder employing very high-dose MA treatment regimens that elicit dopamine neurotoxicity selectively within dorsal striatal regions, cf. [10-12]. While such an approach provided tremendous biochemical insight into how high-dose MA induces forebrain damage of relevance to late-stage addiction, the question of why only certain individuals come to repeatedly abuse MA in the first place and an understanding of the neurobiological substrates underpinning risk for MA Use Disorder have received relatively less experimental attention, cf. [13].

In humans, moderate doses of amphetamine-type stimulants (e.g., $0.1-0.4 \mathrm{mg} / \mathrm{kg}$ ) elicit euphoria and behavioral activation, which are typically considered appetitive/reinforcing. Higher, subtoxic, MA doses (e.g., $1.0-4.0 \mathrm{mg} / \mathrm{kg}$ ) can induce anxiety, cause severe headaches, and stimulate the cardiovascular system, which can be perceived as aversive, cf. [14,15]. As for other drugs of abuse, e.g., [16-21], individual differences in sensitivity to MA's rewarding/aversive effects likely influence risk of continued MA abuse/addiction in humans, which is corroborated by prior literature using murine models of MA Use Disorder risk/resiliency [22-26]; cf. [13]. Of relevance to this report, there is accumulating evidence implicating corticoaccumbens glutamate transmission in gating the affective valence of MA and subsequent drug-taking behavior [26-29], with additional evidence supporting a key role for the mGlu5 subtype of glutamate receptor in MA preference, MA self-administration, and reactivity to MA-associated cues [30-36]. While reports of the expression levels or functional status of mGlu5 in the brains of humans with MA Use Disorder are forthcoming (https:/ / grantome.com/grant/NIH/R33-DA031441-06), MA Use Disorder is associated with lower levels of glutamatergic neurometabolites in frontal cortical regions [37-39], supporting a key role for corticoaccumbens glutamate dysfunction in MA Use Disorder vulnerability and severity.

Extracellular signal-related kinase (ERK) is a member of the mitogen-activated protein kinase (MAPK) signaling cascade and has long been implicated in the neurobiology of Substance Use Disorder, cf. [40-43]. However, its role in MA Use Disorder vulnerability is under-studied, with animal research focused on the nucleus accumbens [44,45]. We reported previously that blunted MA-induced glutamate release and ERK activity within the ventromedial aspect of the PFC (vmPFC) were biochemical traits correlated with selection for high versus low MA-drinking in mice [27]. Here, we extend these immunoblotting findings to isogenic mice spontaneously exhibiting high MA conditioned place-preference (MA-CPP) versus -aversion and examine the functional consequences of pharmacologically targeting ERK activation within vmPFC for MA-conditioned reward/aversion. ERK phosphorylates mGlu5 on T1123 and S1126 and mice with alanine substitutions at these sites exhibit altered behavioral responses to both cocaine [46] and alcohol [47]. Thus, we also characterized MA reward and reinforcement in mGlu5 ${ }^{\mathrm{T11}}{ }^{23 \mathrm{~A} / \mathrm{S} 1126 \mathrm{~A}}$ mice $\left(\mathrm{Grm} 5^{\mathrm{AA} / \mathrm{AA}}\right)$ and their wild-type (WT) controls $\left(\mathrm{Grm} 5^{T S / T S}\right)$ to probe mGlu5 as a potential site of ERKdependent regulation of MA reward and reinforcement.

\section{Results}

\section{1. $p$ ERK Expression within $M P F C$ Predicts the Positive Affective Valence of $M A$}

The CPP Scores (following conditioning with $2 \mathrm{mg} / \mathrm{kg}$, IP) obtained from male B6J mice categorized as CPP, Neutral, and CPA are provided in Figure 1A (see Ref. [26] for detailed analyses of the place-conditioning behavior of these mice). Immunoblots of 
the mPFC failed to detect any group differences in total ERK expression within mPFC (Figure $1 \mathrm{C}$, right; univariate ANOVA, $p=0.17$ ). In contrast, an examination of total and the relative expression of pERK indicated higher ERK activity within the MPFC of CPP animals, relative to the other groups tested (Figure 1C). This observation was confirmed by ANOVA (for total $p E R K, \mathrm{~F}(1,49)=5.53, p=0.003$; LSD post-hoc tests, CPP vs. SAL: $p=0.003$; CPP vs. Neutral: $p=0.006$; CPP vs. CPA: $p=0.001$; for ratio: $\mathrm{F}(1,49)=4.71, p=0.006$; LSD post-hoc tests, CPP vs. SAL: $p=0.002$; CPP vs. Neutral: $p=0.006$; CPP vs. CPA: $p=0.007$ ). Further, both total pERK expression $(\mathrm{r}=0.056, p<0.005, \mathrm{~N}=38$; data not shown) and the ratio of pERK:ERK within mPFC predicted the magnitude of the place-conditioned response (Figure 1D; $\mathrm{r}=0.69, p<0.0001, \mathrm{~N}=38$ ). Thus, MA-preference is predicted by the activational state of ERK within $\mathrm{mPFC}$ of isogenic mice.

\begin{tabular}{|c|c|c|c|}
\hline \multicolumn{2}{|c|}{ ERK correlates of MA-induced place-conditioning } \\
\hline B6J Males & Days 1 & Days 2-9 & Day 10 \\
\hline & Pretest & Place-conditioning & Post-Test \\
\hline Procedures & $\begin{array}{c}\text { Days 2, 4, 6, 8: } \\
\text { SAL inj } \\
\text { both compartments }\end{array}$ & $\begin{array}{c}\text { Days 3, 5, 7, 9: } \\
\text { 2 mg/kg MA } \\
\text { both compartments } \\
\text { 15 min confinement to } \\
\text { appropriate chamber }\end{array}$ & $\begin{array}{c}\text { Determination of } \\
\text { phenotype } \\
\text { Tissue collection for } \\
\text { immunoblotting }\end{array}$ \\
\hline
\end{tabular}

A

\begin{tabular}{|l|l|}
\hline Phenotype & CPP Score (sec) \\
\hline CPA $(n=12)$ & $-223.32 \pm 20.26$ \\
\hline Neutral $(n=12)$ & $-16.45 \pm 17.25$ \\
\hline CPP $(n=14)$ & $312.27 \pm 31.77^{* *}$ \\
\hline
\end{tabular}
\begin{tabular}{l|l} 
Neutral $(n=12)$ & $-16.45 \pm 17.25$ \\
\hline $\operatorname{CPP}(n=14)$ & $312.27 \pm 31.77$ \\
\hline
\end{tabular}

\section{C}

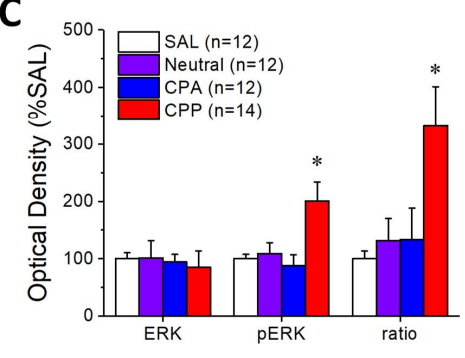

B
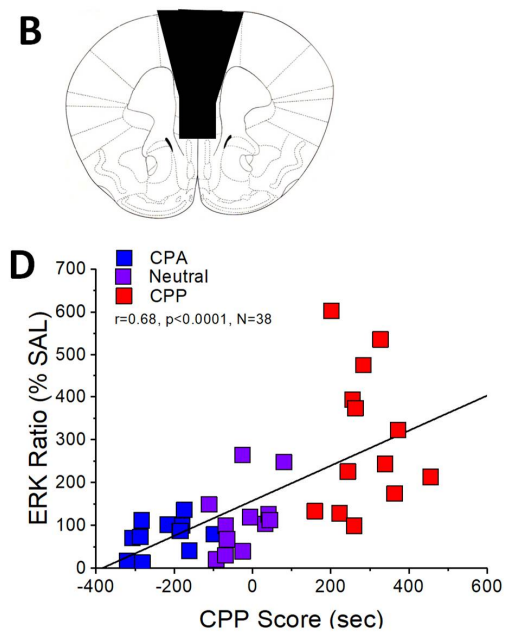

Figure 1. Elevated phospho-ERK expression within $\mathrm{MPFC}$ is a biochemical correlate of the affective valence of methamphetamine. (Inset): Outline of the procedural timeline for the immunoblotting study of ERK correlates of the place-conditioning elicited by the repeated pairing of $2 \mathrm{mg} / \mathrm{kg}$ methamphetamine (MA) in male C57BL/6J mice. Mice were tested for the expression of their conditioned response in a MA-free state (15 min session) and brains removed ( 2-5 min later) for immunoblotting. (A) Summary of the differences in the time spent in the methamphetamine (MA) - versus saline (SAL) - paired compartment of the place-conditioning apparatus between mice spontaneously exhibiting a MA-conditioned place-preference (CPP), a MA-conditioned placeaversion (CPA), and no conditioned response (Neutral). Sample sizes are indicated in parentheses. Note data in Panel A is from Ref. [26]. (B) Cartoon depicting the tissue dissection of the mPFC. (C) Summary of the mPFC levels of total ERK, p(Tyr204)-ERK, and their ratio exhibited by CPP, Neutral, and CPA mice, as well as mice conditioned with SAL. The raw immunoblots are provided in the unpublished materials. (D) Results of the correlational analysis conducted between the CPP Score and the ratio of phosphorylated to total ERK within the mPFC. The data in Panels $(\mathbf{A}, \mathbf{C})$ represent the mean \pm SEMs of the number of mice indicated in parentheses. ${ }^{*} p<0.05$ vs. all other groups; ** $p<0.05$ vs. CPA and Neutral. 


\subsection{U0126 Reduces MA-Induced Place-Preference}

We next sought to gain causal evidence of a role for ERK in MA-preference under place-conditioning procedures in a group of B6J male mice distinct from those employed in the immunoblotting study. Upon removal of the mice expressing a CPA (see Materials and Methods), a comparison of the data obtained during the initial post-conditioning test from the remaining mice slated to receive intra-PFC VEH versus U0126 indicated no group difference in either CPP Score (VEH: $346.23 \pm 70.29$ s; U0126: $278.38 \pm 48.71 \mathrm{~s}$; $\mathrm{t}(15)=0.81, p=0.43$ ) or distance traveled (VEH: $34.52 \pm 2.56 \mathrm{~m}$; U0126: $32.90 \pm 3.20 \mathrm{~m}$; $\mathrm{t}(15)=0.34, p=0.74)$ prior to the onset of microinjection procedures, with both VEH and U0126 mice exhibiting a robust MA-induced place-preference (data not shown; side effect: $\mathrm{F}(1,55)=55.52, p<0.0001$; treatment effect and interaction, $\left.p^{\prime} \mathrm{s}>0.25\right)$.

Intra-mPFC administration of U0126 $(0-100 \mathrm{nM})$ prior to the next four post-tests significantly attenuated CPP scores (Figure 2A) (Treatment effect: $\mathrm{F}(1,15)=6.15, p=0.03$; Side effect: $p=0.56$; interaction: $\mathrm{F}(3,45)=2.59, p=0.065)$. When infused with VEH, both groups exhibited a robust conditioned place-preference (one-sample t-tests, VEH-test1: $\mathrm{t}(5)=3.00, p=0.03$; U0126-vehicle: $\mathrm{t}(10)=4.65, p=0.001)$ and their CPP Scores were superimposable (Figure 2A). Consistent with prior evidence that the expression of a MACPP persists in B6J males [26], VEH-pretreated mice continued to exhibit a robust MA-CPP across the remaining test sessions (one-sample $t$-tests, all $p^{\prime}$ s $<0.002$ ). In contrast, a MA-CPP was absent in mice infused with U0126 (one-sample t-tests, all $p^{\prime}$ s $>0.32$ ). Thus, inhibiting ERK signaling in the vmPFC blocks the expression of a MA-CPP.

Despite its robust effects upon MA-CPP, U0126 infusion did not alter the locomotor activity expressed by the mice during testing (Figure 2B; Treatment $\mathrm{X}$ Dose ANOVA, all $p^{\prime} \mathrm{s}$ $>0.20$ ). Thus, the capacity of an intra-PFC infusion of U0126 to reduce the positive affective valence of MA was unrelated to non-selective effects upon locomotor activity.

\subsection{Transgenic Disruption of ERK-Dependent Phosphorylation of (T1123/S1126)mGlu5 Augments MA-Conditioned Reward}

Grm5 $5^{A A / A A}$ mice exhibit increased alcohol-induced CPP but grossly perturbed cocaineinduced CPP [47]. Given the results above linking ERK activity to MA-conditioned reward, we examined the effects of disrupting ERK-dependent mGlu5 phosphorylation upon the capacity of repeated MA to elicit place-conditioning in a dose-dependent fashion. Interestingly, transgenic disruption of (T1123/S1126)mGlu5 phosphorylation produced a robust increase in the efficacy of MA to elicit a conditioned place-preference (Figure 3 ) (Side effect: $\mathrm{F}(1,68)=30.00, p<0.0001$; Side $X$ Genotype: $\mathrm{F}(1,68)=18.12, p<0.0001$; no other main effects or interactions, $p^{\prime} \mathrm{s}>0.08$ ), with the entire dose-response function of Grm5 $5^{A A / A A}$ mice shifted upwards of Grm5 $5^{T S / T S}$ controls. Thus, ERK-dependent phosphorylation of mGlu5 functions to suppress MA-conditioned reward in a manner similar to alcoholconditioned reward [47].

In line with prior work [46,47], no genotypic differences were noted for the spontaneous locomotor activity expressed during the 15-min pre-conditioning or post-conditioning tests ( $t$-tests, $p=0.18$ and $p=0.58$, respectively; data not shown). Thus, the effect of the Grm5 ${ }^{A A / A A}$ mutation upon MA-conditioned reward does not reflect alterations in spontaneous locomotor activity during testing. 


\begin{tabular}{|c|c|c|c|c|c|c|}
\hline \multicolumn{7}{|c|}{ Intra-PFC U0126 effects on MA-induced place-conditioning } \\
\hline $\begin{array}{l}\text { B6J } \\
\text { Males }\end{array}$ & Days 1-4 & Days 5-11 & Day 12 & Days 13-20 & Day 10 & Days 11-14 \\
\hline & Surgery & Recovery & Pretest & Place-conditioning & $\begin{array}{l}\text { Post-Test } \\
\text { (no } \mu \text {-inj) }\end{array}$ & U0126 Dose-response \\
\hline $\begin{array}{l}\text { Procedu } \\
\text { res }\end{array}$ & $\begin{array}{l}\text { Intra-mPFC } \\
\text { guide } \\
\text { cannulae }\end{array}$ & $\begin{array}{l}\text { Post- } \\
\text { operative } \\
\text { checks } \\
\text { performed } \\
\text { on Days 5-8 }\end{array}$ & $\begin{array}{l}15 \text { min exposure } \\
\text { to both } \\
\text { compartments }\end{array}$ & $\begin{array}{l}\text { Days } 13,15,17,19 \text { : } \\
\text { SAL inj } \\
\text { Days } 14,16,18,10 \text { : } \\
2 \mathrm{mg} / \mathrm{kg} \mathrm{MA} \\
15 \text { min confinement to } \\
\text { appropriate chamber }\end{array}$ & $\begin{array}{l}15 \text { min exposure to } \\
\text { both compartments } \\
\text { Assignment to Rx } \\
\text { groups }\end{array}$ & $\begin{array}{l}\text { Controls: VEH } \mu \text {-inj prior to each test } \\
\text { U0126: } 0,1,10 \text {, or } 100 \mathrm{nM} \text { prior to each } \\
\text { test (randomized across subjects) } \\
15 \text { min exposure to both compartments } \\
\text { End of Day } 14 \text { : Tissue Collection for } \\
\text { histology }\end{array}$ \\
\hline
\end{tabular}
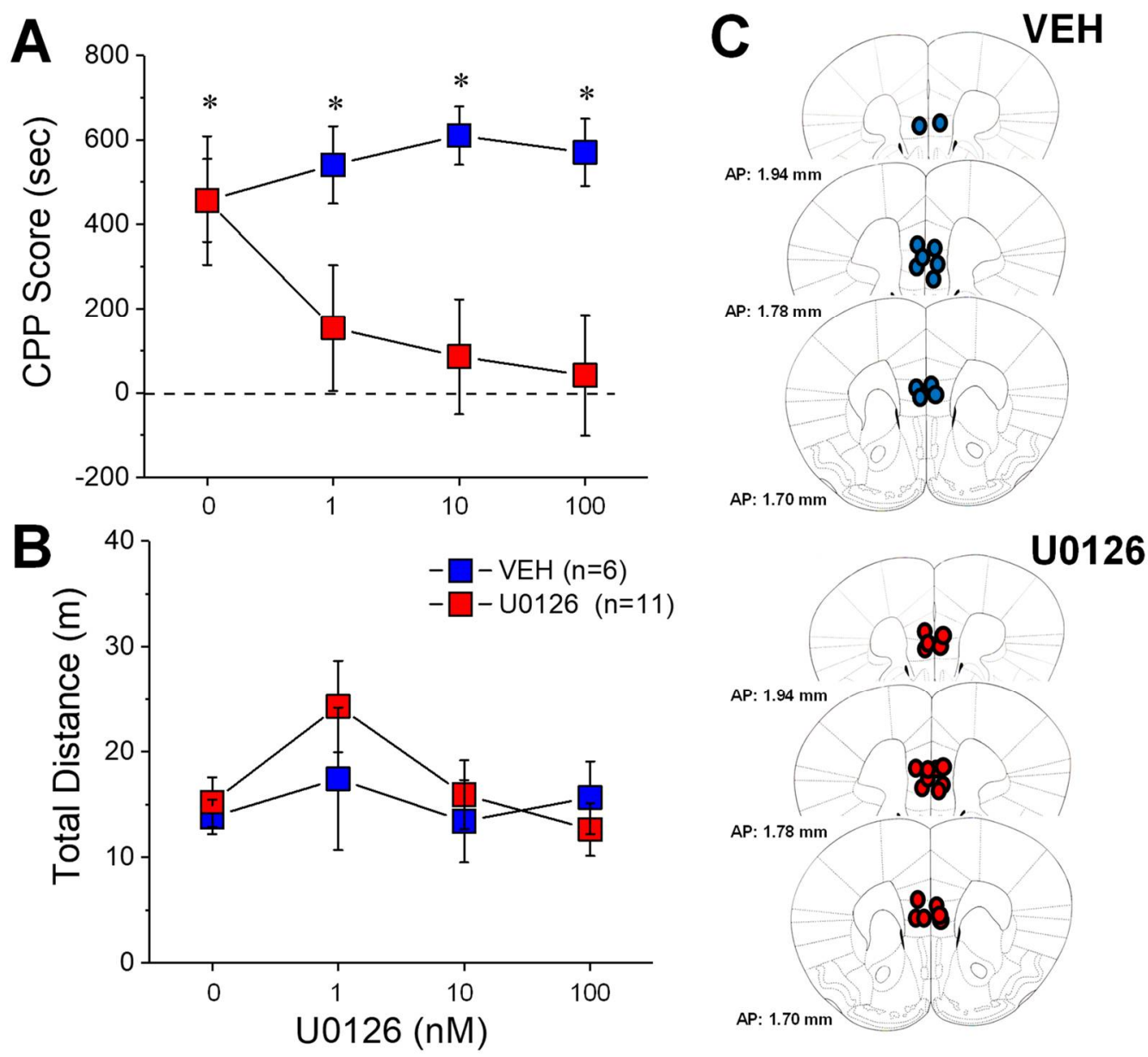

Figure 2. ERK inhibition within the mPFC blocks an established MA-conditioned place-preference, without affecting locomotor activity. (Inset) Procedural time-line for the neuropharmacological study of ERK inhibition upon the expression of a MA-conditioned place-preference. (A) Intra-mPFC infusion of the MEK inhibitor U0126 lowered the expression of a place-preference induced by the repeated pairing of $2 \mathrm{mg} / \mathrm{kg}$ methamphetamine. In contrast, no effect of repeated vehicle (VEH) infusion was detected. (B) U0126 infusion did not alter the locomotor activity of the mice during place-preference testing. (C) Cartoons depicting the locations of the microinjector tips within the $\mathrm{mPFC}$. The data represent the means $\pm \mathrm{SEMs}$ of the number of mice indicated in parentheses. ${ }^{*} p<0.05$ CPP Score vs. 0 (i.e., presence of a conditioned response; 1-sample t-tests). 


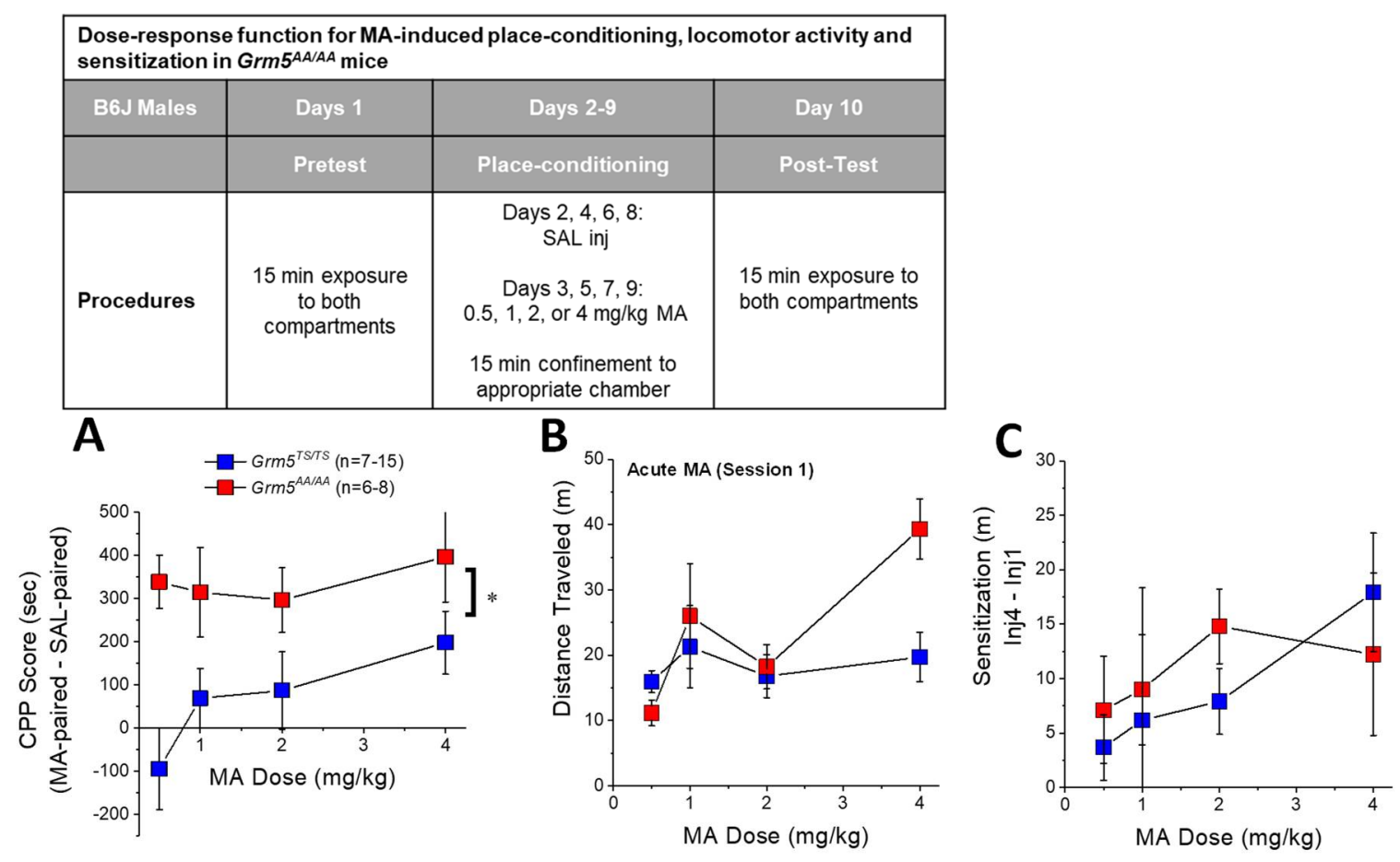

Figure 3. Disruption of ERK-dependent phosphorylation of mGlu5 augments methamphetamine-induced place-preference without affecting methamphetamine-induced psychomotor activity. (Inset) Procedural timeline of the study characterizing the effects of the Grm5 $5^{A A / A A}$ mutation upon MA-induced changes in behavior under place-conditioning procedures. Comparison of the dose-response functions for (A) methamphetamine (MA)-induced place-preference, (B) acute druginduced locomotor activity, and $(\mathrm{C})$ locomotor sensitization (defined as the difference in distance traveled from injection 1 to 4 of MA-conditioning) between WT Grm $5^{T S / T S}$ and mutant Grm5 $5^{A A / A A}$ mice. The data represent the means \pm SEMs of the number of mice indicated in parentheses. ${ }^{*} p<0.05$ (main effect of Genotype).

\subsection{Transgenic Disruption of ERK-Dependent Phosphorylation of (T1123/S1126)mGlu5 Does Not} Affect MA-Induced Locomotion or Locomotor Sensitization

Grm5 ${ }^{A A / A A}$ mice exhibit blunted cocaine-induced locomotor sensitization [46]. Thus, we examined for genotypic differences in MA-induced locomotor activity and for the change in locomotor activity across the four MA-conditioning sessions. Although it appeared that Grm5 $5^{A A / A A}$ were more sensitive to the acute locomotor-stimulating effect of $4 \mathrm{mg} / \mathrm{kg}$ MA (Figure 3B), an analysis of the dose-locomotor response function for acute MA (i.e., on the first conditioning session) did not detect any genotypic difference (Dose effect: $\mathrm{F}(3,74)=4.00, p=0.01$; Genotype effect and interaction, $\left.p^{\prime} \mathrm{s}>0.10\right)$. At all doses, MA-induced locomotor activity sensitized over the course of the four conditioning sessions (Figure 3C) (Dose effect: $\mathrm{F}(3,68)=8.79$; Injection effect: $\mathrm{F}(3,204)=11.92, p<0.0001$; Dose $\mathrm{X}$ Injection: $p=0.26$ ). However, the magnitude of the sensitization did not vary significantly as a function of genotype (Figure 3C) (no Genotype effect or interactions with the Genotype factor, $p^{\prime} s>0.13$ ), owing presumably to the high variability in extent to which MA sensitized responding. Thus, in contrast to our prior results for cocaine [46], ERK-dependent phosphorylation of (T1123/S1126)mGlu5 is not critical for either the psychomotor-activating or -sensitizing effects of MA.

\subsection{Transgenic Disruption of ERK-Dependent Phosphorylation of T1123/S1126-mGlu5 Robustly Attenuates Oral MA Reinforcement and Intake}

Grm5 ${ }^{A A / A A}$ mice exhibit high levels of alcohol reinforcement and intake under operantconditioning procedures [47]. Thus, we next determined in a new cohort of male and female Grm $5^{T S / T S}$ and $G r m 5^{A A / A A}$ mice whether or not transgenic disruption of $\mathrm{p}(\mathrm{T1123/S1126)mGlu5}$ alters motivation for MA and MA intake when drug availability is contingent upon an operant response. 


\subsection{Acquisition of Self-Administration}

As reported previously by our group $[28,48]$, when males and females were trained concurrently, no sex differences were observed for any measure during the five-day acquisition phase of the operant conditioning study (for active hole-pokes, for inactive holepokes, and for MA intake, Sex X Genotype X Day ANOVAs, no sex effects or interactions, $\left.p^{\prime} s>0.24\right)$. Thus, the data were collapsed across sex within each genotype.

When presented with daily opportunities to nose-poke for reinforcement by $20 \mu \mathrm{L}$ of a $10 \mathrm{mg} / \mathrm{L}$ MA solution, $\mathrm{Grm} 5^{A A / A A}$ mice exhibited lower active hole responding, relative to Grm5 $5^{T S / T S}$ mice, irrespective of the day of training (Figure 4A) (Day effect: $\mathrm{F}(4,140)=14.13$, $p<0.0001$; Genotype: $\mathrm{F}(1,35)=11.69, p=0.002$; Genotype X Day: $p>0.10)$. Likewise, Grm5 ${ }^{A A / A A}$ mice also exhibited lower inactive hole responding (data not shown; Genotype effect: $\mathrm{F}(1,35)=4.19, p=0.05$; no Day effect or interaction, $\left.p^{\prime} \mathrm{s}>0.25\right)$, suggesting lower overall behavioral output in the mutant mice. While both genotypes exhibited a progressive decline in their MA intake during training (Figure $4 \mathrm{~B}$ ) (Day effect: $F(4,140)=6.06$, $p<0.0001)$ ), mutant mice exhibited lower MA intake overall during initial training (Genotype effect: $\mathrm{F}(1,35)=18.78, p<0.0001$; interaction: $p=0.29)$. Thus, interfering with ERK-dependent phosphorylation of mGlu5 reduces the initial reinforcing properties, and intake, of a low-dose $10 \mathrm{mg} / \mathrm{L}$ MA solution.

\subsection{MA Demand under Increasing Response Requirement}

When the response requirement for reinforcement by $10 \mathrm{mg} / \mathrm{L}$ MA was progressively increased across days, Grm5 $5^{A A / A A}$ mice maintained their lower level of active hole responding (Figure $4 \mathrm{C}$ ) (Genotype effect: $\mathrm{F}(1,35)=10.39, p=0.003$; interaction, $p>0.35$ ) and similar genotypic differences were apparent also for inactive hole responding (data not shown; Genotype X Schedule: $F(2,70)=9.36, p<0.0001)$. Consistent with prior observations in mice [28,48-50], MA intake dropped precipitously in $\mathrm{Grm} 5^{\mathrm{TS} / T S}$ mice as a function of response requirement (Figure 4D) (Schedule effect: $\mathrm{F}(2,70)=24.82, p<0.0001$ ); however, the MA intake by Grm5 $5^{A A / A A}$ mice was consistently less than that exhibited by Grm5 $5^{T S / T S}$ controls, although the genotypic difference was much more pronounced under the FR1 and FR2 scheduled of reinforcement (Figure 4D) (Genotype effect: $\mathrm{F}(1,35)=23.89, p<0.0001$; Genotype X Schedule: $\mathrm{F}(1,70)=9.96, p<0.0001)$. Thus, mutation of (T1123/S1126)mGlu5 blunts the demand for MA, at least when $10 \mathrm{mg} / \mathrm{L} \mathrm{MA}$ serves as the reinforcer.

\subsection{Dose-Response Function for Oral MA Reinforcement}

Given the precipitous drop in MA intake under the FR5 schedule of reinforcement (Figure 4D), mice were returned to the original FR1 reinforcement schedule to examine for genotypic differences in the dose-response functions for MA reinforcement and intake. Examination of the dose-response function (5-40 mg/L MA) for active hole pokes indicated a shift downwards in Grm5 $5^{A A / A A}$ vs. WT mice (Figure 4E) (Genotype effect: $\mathrm{F}(1,35)=11.02$, $p=0.002$; interaction, $p>0.31$ ), and this genotypic difference was observed also in the cohort tested at the $80 \mathrm{mg} / \mathrm{L}$ dose $(\mathrm{t}(22)=2.54, p=0.02)$. Not shown, we observed no significant genotypic differences in the dose-dependent decline in inactive hole pokes observed during dose-response testing (5-40 mg/L MA: Dose effect: $\mathrm{F}(2,70)=3.98, p=0.02$; Genotype effect and interactions, $\left.p^{\prime} \mathrm{s}>0.10 ; 80 \mathrm{mg} / \mathrm{L}: \mathrm{t}(22)=1.98, p=0.06\right)$, arguing that the genotypic differences in active hole pokes were selective for the MA-reinforced hole. 

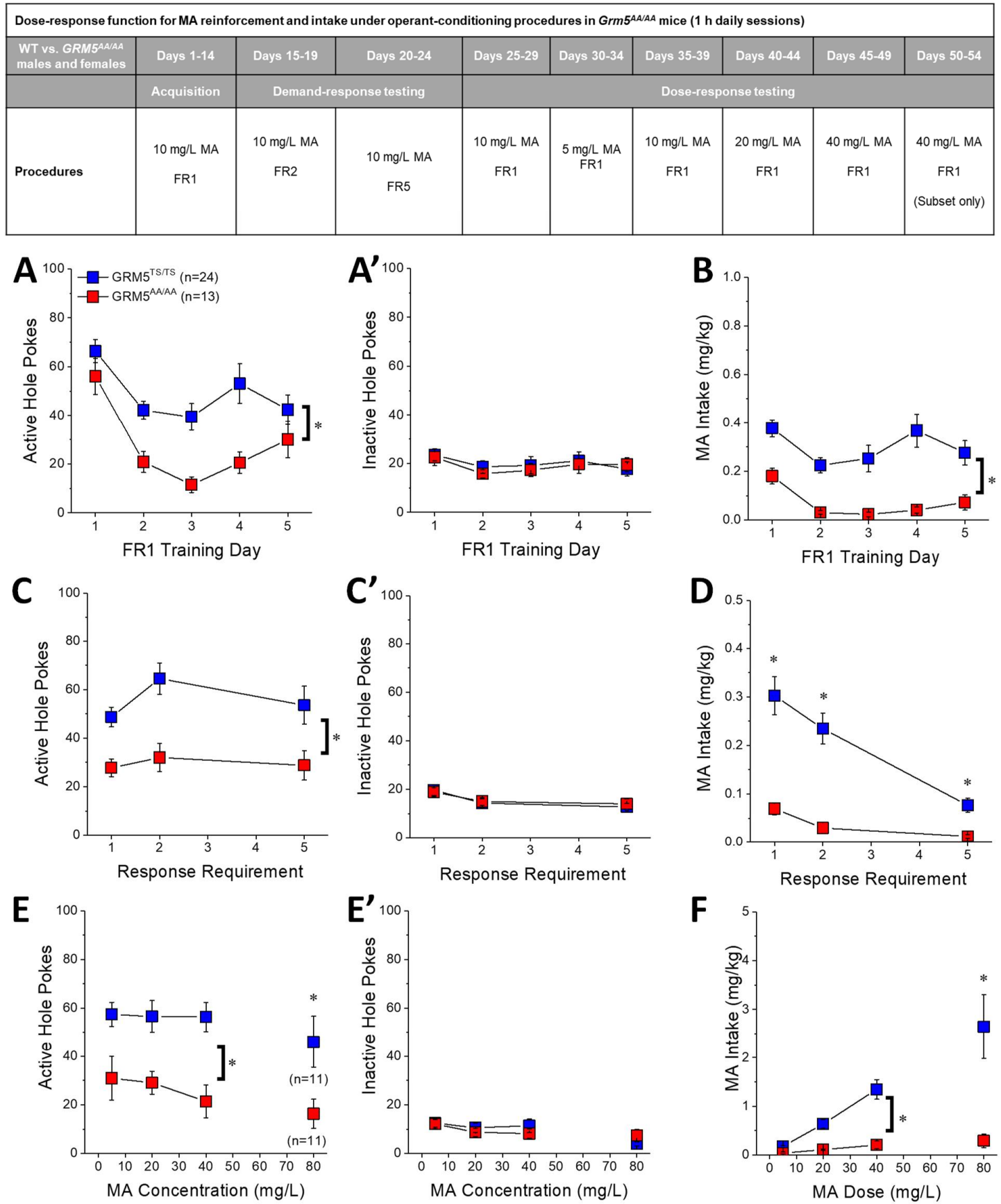

Figure 4. Disruption of ERK-dependent phosphorylation of mGlu5 blunts methamphetamine reinforcement and intake under operant-conditioning procedures. (Inset) Procedural timeline of the operant-conditioning studies conducted in Grm5 $5^{A A / A A}$ and Grm5 $5^{T S / T S}$ mice. When the first five days of self-administration training were considered, Grm $5^{A A / A A}$ mutants exhibited less (A) methamphetamine (MA)-directed responding for reinforcement by $20 \mathrm{mg} / \mathrm{L} \mathrm{MA}$ and (B) less MA intake than WT Grm5 $5^{T S / T S}$ mice. When the response requirement for reinforcement by $20 \mathrm{mg} / \mathrm{L}$ MA progressively increased, mutant mice continued to exhibit (C) less MA-directed responding and (D) less intake. When the dose of the MA reinforcer varied under an FR1 schedule of reinforcement, the MA-directed responding (E) and MA intake (F) continued to be lower in Grm5 $5^{A A / A A}$ mice versus Grm5 $5^{T S / T S}$ controls. No genotypic differences were detected for responding in the inactive hole during $\left(\mathbf{A}^{\prime}\right)$ early training, $\left(\mathbf{C}^{\prime}\right)$ demand testing, or $\left(\mathbf{E}^{\prime}\right)$ dose-response testing. The data represent the means \pm SEMs of the number of mice indicated in parentheses. Note: not all mice tested for reinforcement by $5-40 \mathrm{mg} / \mathrm{L} \mathrm{MA}$ advanced to testing under the $80 \mathrm{mg} / \mathrm{L}$ dose. ${ }^{*} p<0.05$ (main Genotype effect); ${ }^{*} p<0.05 \mathrm{vs}$. Grm $5^{\text {TS/TS }}$ ( $t$-test).

Consistent with their results obtained during early and later acquisition of selfadministration (Figure 4B,D), Grm5 $5^{A A / A A}$ mice continued to exhibit very low levels of 
oral MA intake during dose-response testing (Figure 4F). Although the magnitude of the genotypic difference in intake increased as a function of MA concentration (Figure 4F) (Genotype $X$ Dose: $F(2,68)=14.42, p<0.0001$ ), significant group differences were detected at every MA concentration ( $t$-tests, all $\left.p^{\prime} s<0.0001\right)$, with the largest genotypic difference in intake apparent in the cohort tested at $80 \mathrm{mg} / \mathrm{L} \mathrm{MA}$ (Figure $4 \mathrm{~F}$, right) $(\mathrm{t}(22)=20.53$, $p=0.001)$. While these data argue that $\mathrm{p}(\mathrm{T} 1123 / \mathrm{S} 1126) \mathrm{mGlu} 5$ is necessary for MA reinforcement and intake under operant-conditioning procedures, based on the results from the place-conditioning study (Figure 3A), we propose that the blunted MA reinforcement and intake exhibited by Grm $5^{A A / A A}$ mice might reflect compensation for their heightened sensitivity to the primary rewarding properties of this drug.

\subsection{Transgenic Disruption of ERK-Dependent Phosphorylation of (T1123/S1126)mGlu5 Blunts Oral MA Intake under DID Procedures}

Another possibility to account for the discrepancy in findings between our placeand operant-conditioning experiments might relate to a genotypic difference in MA taste sensitivity. Thus, we next compared Grm5 $5^{A A / A A}$ and $G r m 5^{T S / T S}$ mice for oral MA intake under DID procedures in a distinct cohort of MA-naïve female mice. To our surprise, no genotypic difference was detected for the dose-response function for MA intake in the home cage (Figure 5A) (Concentration effect: $\mathrm{F}(3,72)=11.46, p<0.0001$; Genotype effect and interaction, $p^{\prime} \mathrm{s}>0.30$ ) or for the average total MA consumed over the course of the study (Figure 5B; $t$-test, $p=0.30$ ). Thus, the low MA intake exhibited by Grm $5^{A A / A A}$ mice does not appear to reflect a shift in MA taste sensitivity, or other factors associated with the capacity to drink MA.

\begin{tabular}{|c|c|}
\hline \multicolumn{2}{|c|}{ MA intake in the home-cage by Grm5AA/AA female mice } \\
\hline WT vs. GRMI5AA/AA females & Days 1-7 \\
\hline $1200 \mathrm{~h}:$ & Mice housed in test cage \\
$1300 \mathrm{~h}:$ & Bottles on: $5,10,20 \& 40 \mathrm{mg} / \mathrm{L} \mathrm{MA}$ \\
$1500 \mathrm{~h}:$ & Bottles removed \& mice returned to home cage \\
\hline
\end{tabular}
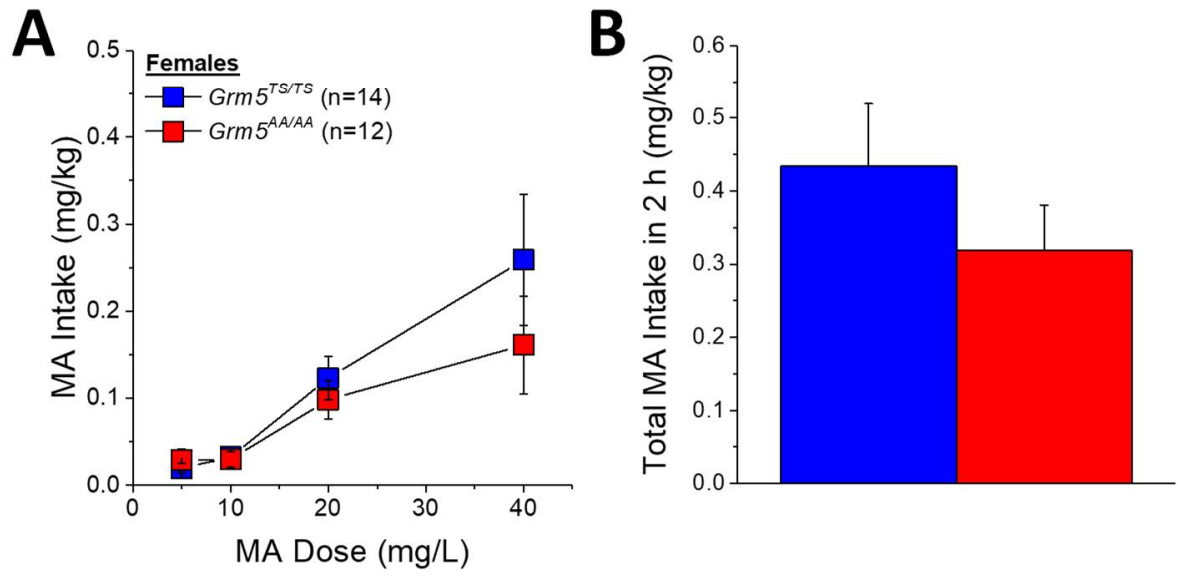

Figure 5. Disruption of ERK-dependent phosphorylation of mGlu5 only modestly blunts MA intake in the home cage. When presented simultaneously with four sipper tubes containing, 5, 10, 20, and $40 \mathrm{mg} / \mathrm{L} \mathrm{MA}$, (A) Grm5 $5^{A A / A A}$ mice tended to consume less $40 \mathrm{mg} / \mathrm{L} \mathrm{MA}$ and (B) exhibited lower overall MA intake than their WT Grm $5^{T S / T S}$ controls. Neither of the genotypic differences were statistically reliable. The data represent the means \pm SEMs of the number of mice indicated in parentheses. 


\section{Discussion}

The present study demonstrates that ERK hyperactivity within MPFC is a biochemical correlate of individual differences in the perception of MA's interoceptive effects as rewarding. A directed neuropharmacological study provides causal evidence that mPFC ERK function is required for the positive affective valence of MA expressed by mice under place-conditioning procedures. Peculiarly, transgenic global disruption of ERK-dependent phosphorylation of (T1123/S1126)-mGlu5 increased sensitivity to MA's positive affective properties, while markedly blunting MA reinforcement and intake under operant-conditioning procedures. The low MA intake exhibited by $G r m 5^{A A / A A}$ mutants under operant-conditioning procedures cannot readily be accounted for by differential MA taste sensitivity, as no genotypic difference in home-cage MA-drinking was observed. Our findings are consistent with a key role for ERK hyperactivity within MPFC in driving the expression of MA-conditioned reward, but argue that (T1123/S1126)-mGlu5 within the mPFC is not likely the target involved. In contrast, ERK-dependent phosphorylation of (T1123/S1126)-mGlu5 is necessary for MA reinforcement, which may reflect actions within the MPFC or perhaps other mesocorticolimbic sites known to regulate MA selfadministration behavior.

\subsection{Individual Differences in MA-Preference Are Positively Correlated with ERK Hyper-Activity} within PFC

Similar to other addictive substances, a relatively small proportion of individuals who use MA recreationally develop MA Use Disorder. Over the past several years, we have employed an integrative approach to understand the neurobiological bases for individual differences in vulnerability to MA Use Disorder that includes the study of isogenic B6J mice spontaneously exhibiting MA-preference, -neutrality, or -aversion under place-conditioning procedures [26,27,50,51]. While we [27] and others, e.g., [42,52], have failed to detect an effect of repeated MA injections upon basal ERK phosphorylation within PFC, increased pERK expression is reported consistently in rodents expressing a MA-CPP (Figure 1; [52,53]), indicating that increased ERK activity within the MPFC is a response to the MA-associated environment, rather than MA administration per se-a finding consistent with an earlier MA-induced place-conditioning study in mice [51].

Providing our first piece of evidence that phospho-ERK expression within mPFC may drive MA-conditioned reward, herein, we identified $\mathrm{p}$ (Tyr204)ERK1/2 within the MPFC as a biochemical correlate of the affective valence of MA in male B6J mice (Figure 1D). Despite all mice receiving equivalent subchronic MA treatment as well as CPA and CPP mice exhibiting place conditioning effects of similar magnitude, an increase in both the total and relative expression of $\mathrm{p}$ (Tyr204)-ERK was observed only in mice expressing a CPP (Figure 1B,C), with CPA and neutral mice exhibiting similar levels of protein expression as MA-naïve, saline-conditioned controls (Figure 1C). These immunoblotting results for B6J males spontaneously expressing a MA-CPP align with the results of our earlier report in which we detected a modest increase in basal p(Tyr204)-ERK expression within the MPFC of male and female MA-naïve mice selectively bred for high MA-drinking (MAHDR), relative to their low-drinking (MALDR) counterparts [27]. Noteworthily, MAHDR exhibit, respectively, increased and decreased sensitivity to the conditioned rewarding and aversive properties of MA under place-conditioning procedures [22,24]. Taken all together, this body of correlational evidence implicates ERK hyper-activation within mPFC in driving the positive affective valence of MA and suggests drug cue/context-elicited ERK activation as at least one molecular contributor to the metabolic hyperactivity reported within the frontal cortex of individuals with MA Use Disorders in response to MA-associated stimuli, e.g., [54-56]. 


\subsection{Local Inhibition of mPFC ERK Phosphorylation Eliminates an Established MA-CPP Phenotype}

Confirming the functional relevance of MPFC ERK for the expression of MA-conditioned reward, site-directed infusion of the MEK inhibitor U0126 reduced the magnitude of MA-CPP in B6J mice, with the lowest $1.0 \mathrm{nM}$ dose effectively blocking CPP expression (Figure 2A). Notably, all of the mice in this study expressed a robust MA-CPP prior to microinfusion procedures, and thus we conclude that U0126 eliminated an established MA-CPP. Importantly, intra-mPFC U0126 infusion did not alter the locomotor activity of the mice at any point during testing (Figure 2B), indicating no off-target motor effects that might confound data interpretation. As reported previously by our group [26], the expression of MA-CPP is persistent in mice, as indicated by the stable conditioned approach response exhibited by control mice receiving daily VEH microinjections (Figure 2A). This finding for VEH controls, coupled with the fact that U0126 dosing was counter-balanced across test days, argues against potential factors associated with repeated microinjection (e.g., tissue damage) as a major contributing factor to our observed U0126 effects.

ERK activation by MEK requires phosphorylation at both Thr202 and Tyr204, e.g., [57]. While we only assayed the Tyr202 phosphorylation site in our immunoblotting study (Figure 1C), the present U0126 data provide evidence that MEK-mediated activation of ERK within the $\mathrm{mPFC}$ is required for contextual control over MA-directed approach behavior. It remains to be determined whether or not intra-PFC infusion of U0126 during methamphetamine-conditioning prevents the development of the conditioned reward or aversion. However, our data extend to the $\mathrm{MPFC}$, the results of earlier drug-induced place-conditioning studies in which systemic pretreatment with ERK inhibitors [58-62] or targeted ERK inhibition within the nucleus accumbens [51,63] were reported to inhibit drug-induced place-preference in rodents. The present data also align with other studies linking the efficacy of potential anti-addiction medications at blocking CPP with a reduction in phospho-ERK expression within $\mathrm{mPFC}$, e.g., [53,64].

\subsection{Grm5 $5^{A A / A A}$ Mice Exhibit More Robust MA-CPP}

Contrary to our MA-CPP results for U0126 (Figure 2A), Grm5 $5^{A A / A A}$ mice with disrupted ERK-dependent mGlu5 phosphorylation exhibit increased MA-CPP across an approximately 10-fold range of MA doses (Figure 3A). These results were not entirely unanticipated, as Grm5 $5^{A A / A A}$ mice also exhibit greater alcohol-induced CPP than Grm5 $5^{T S / T S}$ (WT) controls [47]. It is important to note, however, that unlike the present findings for MA-CPP (in which the entire dose-response function is shifted upwards in Grm5 $5^{A A / A A}$ mice versus WT controls; Figure 3A), the augmented alcohol-CPP exhibited by Grm5 $5^{A A / A A}$ mice reflects a shift to the right in the dose-response function for alcohol-CPP; Grm5 $5^{A A / A A}$ mice exhibit no conditioned response to low alcohol doses that effectively elicit a CPP in WT controls and an insensitivity to the conditioned aversive properties of higher alcohol doses [47]. Despite conditioning with doses as high as $4 \mathrm{mg} / \mathrm{kg}$ MA, we did not detect a high-dose MA-CPA in WT controls. However, it is interesting to note that Grm5 $5^{A A / A A}$ mice exhibit a robust MA-CPP at the lowest MA dose tested herein $(0.5 \mathrm{mg} / \mathrm{kg})$, while WT controls trended towards a CPA (Figure 3A). The blunted sensitivity to alcohol-CPA exhibited by Grm5 ${ }^{A A / A A}$ mice is attributed to ERK-dependent phosphorylation of mGlu5 within the bed nucleus of the stria terminalis (BNST) as the effects of an intra-BNST infusion of U0126 recapitulate the alcohol-CPP phenotype of Grm5 $5^{A A / A A}$ mice [47]. To the best of our knowledge, the role for the BNST in regulating the affective valence of MA is unexplored. Clearly, the opposite MA-CPP effects of intra-PFC U0126 infusion versus the T1123A/S1126A mutation of mGlu5 argue that the mPFC is not a neural locus involved in driving the MA-CPP phenotype of $G r m 5^{A A / A A}$ mice. Based on our prior studies of alcoholCPP in Grm $5^{A A / A A}$ mice [47], the BNST may play a key role in MA-CPP/CPA. Alternatively, accumulating evidence indicates a cross-sensitization between the rewarding properties of alcohol and MA $[49,65,66]$ that we theorize reflects common glutamate-related neuroadaptations within the nucleus accumbens (see Ref. [26] for discussion). ERK-dependent 
signaling within the nucleus accumbens is required for the expression of amphetamineand MA-CPP [51,63], raising the possibility that this brain region may be a potentially important site contributing to the MA-CPP phenotype of $G r m 5^{A A / A A}$ mice.

Although the neural loci contributing to the MA-CPP phenotype of $G r m 5^{A A / A A}$ remain to be characterized, it should be noted that the heightened MA-CPP exhibited by Grm5 ${ }^{A A / A A}$ mice does not generalize to cocaine. In fact, both $G r m 5^{A A / A A}$ and heterozygous $G r m 5^{T S / A A}$ mice exhibit a very strong cocaine-CPA at doses that elicit a robust CPP in WT controls [47]. Further, the T1123A/S1126A mutation of mGlu5 abolishes cocaine-induced behavioral sensitization and neurochemical sensitization within the nucleus accumbens [46], the latter of which might contribute to their cocaine-averse phenotype, as cocaine-CPA is associated with blunted dopamine and glutamate sensitization within NAC [67]. Although the present study did not characterize the neurochemical phenotype of MA-treated Grm5 $5^{A A / A A}$ mice, we have reported that MA experience induces changes in extracellular glutamate and glutamate-related protein expression within the PFC and NAC that are not only distinct from, but sometimes opposite those produced by repeated cocaine treatment $[26,29]$. Whether or not the (T1123A/S1126A)-mGlu5 mutation also affects MA-induced glutamate plasticity within the NAC, $\mathrm{mPFC}$, or other addiction-relevant brain regions (e.g., BNST) is an important next step to account for the polar opposite effects of the (T1123A/S1126A)mGlu5 mutation upon the affective valence of cocaine versus MA and alcohol.

\subsection{Grm5 $5^{A A / A A}$ Mice Exhibit Reduced Oral MA Self-Administration}

From the outset of operant-conditioning procedures, Grm5 $5^{A A / A A}$ mice exhibited lower MA reinforcement and intake, compared to Grm $5^{T S / T S}$ controls (Figure 4). Although Grm5 ${ }^{A A / A A}$ also exhibit lower sucrose self-administration under operant-conditioning procedures, they are reported to exhibit higher alcohol reinforcement and intake versus WT controls [47]. Thus, the low-level MA self-administration observed herein does not likely reflect an operant-learning, motivational, or motor deficit secondary to the mutation. Moreover, as the amount of MA consumed during training was relatively low $(<0.5 \mathrm{mg} / \mathrm{kg}$ $\mathrm{MA} /$ day), it is also not likely that the low level of responding/intake reflects the induction of stereotyped behavior that might interfere with the operant response. While we did not monitor motor activity during self-administration procedures, the fact that no genotypic difference in MA-induced locomotion was detected during place-conditioning procedures (Figure 3B,C) when mice were repeatedly administered MA doses well in excess of the doses consumed during operant-conditioning also argues against differential sensitivity to MA's psychomotor effects as contributing to the markedly blunted MA reinforcement exhibited by $G r m 5^{A A / A A}$ mice.

The genotypic difference in MA-reinforced responding was apparent from the second day of training under an FR1 schedule of reinforcement and persisted throughout training (Figure 4A). As reported previously in female and male B6J mice [48-50], MA-directed responding does not vary much with increasing response requirement (Figure 4C), but the intake of low-concentration MA drops precipitously with increasing demand (Figure 4D). Such findings argue that mice do not find low-concentration MA particularly reinforcing. As B6J mice consume less MA than mice on other genetic backgrounds (e.g., DBA2/J) [68,69], it remains to be determined whether or not the low MA demand and intake observed in our studies to date reflect the B6J genetic background of the mice or the relatively low training doses employed in our studies. Nevertheless, our procedures are sufficient to detect robust genotypic differences in both MA-directed responding and intake $[28,48]$ (Figure $4 \mathrm{C}, \mathrm{D})$, to further the notion that ERK-dependent phosphorylation of mGlu5 is necessary for MA reinforcement.

Grm5 $5^{A A / A A}$ mice exhibit consistently lower MA-directed responding and intake than WT controls across a greater than 10-fold range of MA concentrations (5-80 mg/L). In fact, the genotypic difference in daily MA intake widens as a function of the MA reinforcer concentration (Figure 4F), and this genotype X MA dose interaction is apparent also in our study of MA drinking in the home cage (Figure 5A). The consistently low levels 
of MA-directed responding exhibited by $G r m 5^{A A / A A}$ mice are indicative of lower MA reinforcement, which is difficult to reconcile with their more robust MA-CPP phenotype (Figure 3A). Differential bitter tastant sensitivity is unlikely to be a factor contributing to the lower intake of MA during behaviorally contingent access, because no genotypic differences were apparent under home-cage drinking procedures (Figure 5A). Given the robust MA-CPP phenotype of the $G r m 5^{A A / A A}$ mice, it is possible that their low level of MA reinforcement may reflect a compensation for their increased sensitivity to MA's rewarding properties.

\section{Materials and Methods}

\subsection{Subjects}

Adult (eight weeks of age) male inbred C57BL/6J (B6J) mice were purchased from Jackson Laboratories (Sacramento, CA, USA), and housed in groups of four in a temperature $\left(25^{\circ} \mathrm{C}\right)$ - and humidity $(71 \%)$-controlled colony room, under a 12 -h reverse light cycle (lights off: 10:00 h). Heterozygous breeder pairs of transgenic mice with alanine substitution mutations at T1123 and S1126 sites on mGlu5 were obtained from the laboratory of Dr. P.F. Worley (Johns Hopkins University School of Medicine, Baltimore, MD, USA) (generated as described in Refs. $[46,70])$ and used to generate $G r m 5^{T S / T S}$ and $G r m 5^{A A / A A}$ offspring. Mice bred in-house remained multi-housed with same-sex littermates throughout experimentation. All studies of mutant mice employed both male and female littermates from at least three different litters, with each experimental condition consisting of approximately equal numbers of male and female mice. As no sex difference or interactions with sex were detected during statistical analyses, the data for males and females are collapsed for presentation. The Grm5 $5^{T S / T S}$ and Grm5 ${ }^{A A / A A}$ mice were tested between seven and 15 weeks of age, and food and water were available ad libitum throughout the entire study unless otherwise indicated. The experiments followed a protocol consistent with $\mathrm{NIH}$ guidelines presented in the recently revised Guide for Care and Use of Laboratory Animals (2014) and approved by the IACUC of the University of California, Santa Barbara, CA, USA (protocol numbers 829.1, approved 8 May 2014 and 829.2, approved 27 March 2017).

\subsection{Place-Conditioning and Locomotor Activity}

The MA place-conditioning procedures employed in the present experiments were identical to those described previously by our group [26-28,48-50] and are outlined in the inset of Figure 1. Place-conditioning commenced with a pre-conditioning test in which animals were allowed to freely explore both compartments of the place-conditioning chambers in a drug-free state to habituate them to the apparatus. Overall, there was no preference for one compartment versus the other during this pre-test, indicating that the apparatus, itself, was unbiased. Mice were then injected intraperitoneally (IP) with $2 \mathrm{mg} / \mathrm{kg}$ MA ( $\mathrm{vol}=10 \mathrm{~mL} / \mathrm{kg}$ ) and randomly confined to one compartment and, on alternating days, were injected with saline and confined to the alternate compartment for a total of 4 pairings each. The day following the last conditioning session, a post-conditioning test was conducted in which animals were again allowed free access to both chambers in a drug-free state, and the difference in the time spent in the MA- versus saline-paired compartment (i.e., CPP Score in sec) was used to index the direction and magnitude of the place-conditioning.

As detailed previously $[26,27,71]$, for our examination of the ERK correlates of MA place-conditioning in C57BL/6 J mice, we removed brain tissue within 2-5 min of test completion. Mice exhibiting a CPP Score $>+100 \mathrm{~s}$ were phenotyped as "MA-preferring" (CPP), mice exhibiting a CPP Score $<-100$ s were phenotyped as "MA-avoiding" (CPA), and mice exhibiting CPP Scores between -100 and +100 s were phenotyped as "MAneutral" (Neutral).

For the study of ERK-dependent regulation of MA-conditioned reward, only CPP and neutral mice were included, as conducted in prior neuropharmacological studies by our group $[26,27,71]$. In all, six out of the original 32 mice involved in the neuropharmaco- 
logical study that exhibited a CPA (i.e., 16\%) did not undergo microinjection procedures. This proportion of CPA mice is consistent with recently published work [26,50], indicating that a relatively small subpopulation of B6J mice perceive the interoceptive effects of 2 $\mathrm{mg} / \mathrm{kg}$ as aversive. The remaining $\mathrm{B} 6 \mathrm{~J}$ mice were then slated to receive intra-PFC infusions of either vehicle (VEH) or various doses of the ERK inhibitor U0126, immediately prior to each subsequent post-conditioning test (see below for details).

The MA-induced place-conditioning phenotype of $G r m 5^{A A / A A}$ mice was determined using a between-subjects design in which different groups of mice of both sexes were conditioned with $0.5,1,2$, or $4 \mathrm{mg} / \mathrm{kg}$ MA to establish a dose-response function. In our experience [28,48-50] and as reported by others [23,24], this dose-range is sufficient to detect group differences in the affective valence, as well as locomotor-stimulating effects, of MA. With the exception of dosing, the place-conditioning procedures employed in our study of Grm5 $5^{T S / T S}$ and $G r m 5^{A A / A A}$ mice were identical to those employed in our study of B6J mice.

Each place-conditioning session was $15 \mathrm{~min}$ in duration, and throughout conditioning and testing, the total distance traveled was also recorded to examine for off-target effects of U0126 infusion and genotypic differences in MA-induced psychomotor activation and sensitization $[26-28,48,50,65,66,71,72]$.

\subsection{Operant-Conditioning for Oral Methamphetamine Reinforcement}

To examine the effects of the Grm5 $5^{A A / A A}$ mutation upon MA reinforcement and intake, we trained female and male Grm5 $5^{A A / A A}\left(n=23 ; 12\right.$ females and 11 males) and $\operatorname{Grm}^{T S / T S}(n=14$; seven females and seven males) mice to nose-poke for oral MA using operant-conditioning procedures similar to those described in recent studies by our group [26,28,48-50,52]. An outline of the operant-conditioning procedures is provided in the inset of Figure 4. Mice were placed into standard mouse operant-conditioning chambers (MedAssociates, St Albans, VT, USA), equipped with two nose-poke holes with a liquid receptacle between them. One hole (the "active", MA-associated hole) delivered $20 \mu \mathrm{L}$ of the reinforcer from an infusion pump when activated, along with the simultaneous presentation of a 20-s tone/light compound stimulus. The MA reinforcer was dissolved in potable tap water at the concentrations denoted below. During the 20-s activation period, further nose-pokes in the active hole were recorded but did not result in any programmed consequences. Nose-pokes in the opposite hole (the "inactive", MA-unpaired hole) had no programmed consequences but were recorded to determine reinforcer efficacy. Chambers were ventilated and soundattenuated. Conditioning began with a five-day training period on an FR1 reinforcement schedule (one nose-poke/reinforcer) using a $10 \mathrm{mg} / \mathrm{L}$ MA reinforcer, after which mice were removed from the study if they failed to allocate $70 \%$ of their total responding towards the active hole and/or failed to emit at least 10 active nose-pokes during the 1-h session. The mice that met both acquisition criteria were then tested for reinforcement by $10 \mathrm{mg} / \mathrm{L}$ MA under an FR2 and then an FR5 schedule (two nose-pokes/reinforcer and five nose-pokes/reinforcer, respectively) for five days each. Reinforcement schedule was then dropped back to FR1 and reinforcer concentrations switched to $5 \mathrm{mg} / \mathrm{L}, 20 \mathrm{~g} / \mathrm{L}$, and $40 \mathrm{mg} / \mathrm{L}$, each for five days, to determine genotypic differences in the dose-response function for MA reinforcement. Initially, our IACUC limited the maximum MA reinforcer concentration to $40 \mathrm{mg} / \mathrm{L}$. However, having demonstrated that this concentration clearly lay on the ascending limb of the dose-intake function (see below; see also Refs. [26,49,50]), we were allowed to assay a distinct cohort of mice at $80 \mathrm{mg} / \mathrm{L}$ MA. For this additional cohort, $G r m 5^{A A / A A}$ and $G r m 5^{T S / T S}$ mice $(n=11 /$ genotype) were trained to self-administer $10 \mathrm{mg} / \mathrm{L}$ MA under the FR1 training schedule and then tested only at the $80 \mathrm{mg} / \mathrm{L}$ dose on the same FR1 schedule.

To determine individual MA intake for each session, mice were returned to their home cages, and the volume of reinforcer left in the liquid receptacle of each chamber was measured by pipetting. The volume remaining was subtracted from the total volume delivered (i.e., number of reinforcers $\times 20 \mu \mathrm{L}$ ) and then expressed as a function of body weight to determine MA intake (on a $\mathrm{mg} / \mathrm{kg}$ body weight basis). Body weight was 
determined weekly. For the mice undergoing dose-response testing, the average number of active nose-pokes, the ratio of active vs. total nose-pokes, and MA intake were analyzed by a mixed ANOVA, with repeated measures on the factors of Training Day, Reinforcement Schedule, or MA Dose. The data from the cohort of mice that was tested at the $80 \mathrm{mg} / \mathrm{L}$ were analyzed using a $t$-test across the Genotype factor. Two-tailed Pearson correlational analyses were also conducted to relate dependent measures with CPP Score $(\alpha=0.05)$.

\subsection{Methamphetamine Intake under Drinking-in-the-Dark Procedures}

To examine the effects of the Grm5 $5^{A A / A A}$ mutation upon MA intake under behaviorally noncontingent drug-access procedures, we employed a modified version of the drinkingin-the-dark (DID) procedure, in which female $\operatorname{Grm}^{T S / T S}(n=14)$ and female Grm5 $5^{A A / A A}$ $(n=12)$ mice were presented simultaneously with sipper tubes containing $5,10,20$, and $40 \mathrm{mg} / \mathrm{L}$ MA solutions and allowed to drink for a 2-h period (see inset in Figure 5). Only females were employed in this study due to a limited number of male subjects at the time of testing. Females are reported to consume more oral MA than males under certain operant-conditioning procedures [25,48,50], although a sex difference in MA-drinking in the home cage has not been reported in the extant literature, e.g., $[13,22]$. As conducted in a prior studies of MA-drinking in B6J mice [26] and alcohol-drinking in Grm5 $5^{T S / T S}$ versus $\mathrm{Grm} 5^{A A / A A}$ mice [47], mice were single-housed in drinking cages lined with sawdust bedding for a minimum of $1 \mathrm{~h}$ to habituate to the drinking environment. MA bottles were presented for a $2-\mathrm{h}$ period, beginning at $3 \mathrm{~h}$ into the dark phase of the circadian cycle. Upon completion of the 2-h drinking session, the mice were returned to their home cages, the difference in bottle weight before and after the drinking session was used to determine the volume consumed from each solution, and the data were expressed as the mg of MA consumed per kg body weight. Mice underwent MA-DID procedures for a period of seven days, and the average MA intake under DID procedures were analyzed using a Genotype $X$ Concentration ANOVA, with repeated measures on the Concentration factor.

\subsection{Stereotaxic Surgery, U0126 Microinjection, and Histology}

B6J mice slated for microinjection underwent stereotaxic surgery to implant stainless steel guide cannulae ( $7 \mathrm{~mm}, 26$ gauge; Eagle Stainless; Warminster, PA, USA) above the mPFC using procedures identical to those described in our prior work, e.g., $[27,71,73]$. All surgeries were performed under isoflurane anesthesia (1.5-2\%), using oxygen as the carrier gas. Once anesthetized, a mouse was placed in a Kopf stereotaxic device, and its head was stabilized with tooth and ear bars. The skull was then exposed and leveled. Holes were drilled based on coordinates from Bregma (AP: $+1.8 \mathrm{~mm}, \mathrm{ML}: \pm 0.5 \mathrm{~mm}$; DV $-1.0 \mathrm{~mm}$ ), according to the Paxinos and Franklin (2007) mouse brain atlas. The guide cannulae were then lowered to $2 \mathrm{~mm}$ above the $\mathrm{mPFC}$ and were fixed in place with light-cured dental resin. Surgical incisions were closed, using tissue adhesive as necessary. Dummy cannulae (30 gauge; length equivalent to guide cannulae) were inserted into the guide cannulae to reduce externalization. Animals were administered the non-steroidal, anti-inflammatory banamine $(2 \mathrm{mg} / \mathrm{kg}, \mathrm{SC})$, once during the surgical procedure and then twice a day for the first $48 \mathrm{~h}$ post-operation. Animal health was monitored daily following surgery, and all mice were allowed at least five days recovery prior to commencing place-conditioning procedures as described above. Following MA-conditioning, a post-test was conducted, prior to which none of the mice received any intracranial treatment. This was done to (1) ensure equivalent conditioned behavior and locomotor activity across the pretreatment groups prior to microinjections and (2) to identify and remove from the study any mice expressing a CPA.

As outlined in the inset of Figure 2, a within-subjects design was employed to assay the effects of an intra-mPFC infusion of varying doses of the MEK1/2 inhibitor U0126 (0$100 \mathrm{nM}$ ) [74] upon the expression of the MA-conditioned response. U0126 inhibits MEK1/2dependent activation of ERK [74], and U0126 doses were selected based on data from our laboratory indicating their effectiveness at altering alcohol consumption when infused 
intracranially in B6J mice [47]. Approximately 5-7 min prior to the post-test, dummy cannulae were removed, and microinjectors (30-gauge, $9 \mathrm{~mm}$ long) were lowered bilaterally through the guide cannulae into the mPFC. A $1 \mu \mathrm{M}$ stock solution of U0126 was prepared by dissolving in water and aliquots stored at $-80{ }^{\circ} \mathrm{C}$ until use. Fresh U0126 working solutions were prepared daily by diluting the stock with sterilized water for injection and then infused at a rate of $0.5 \mu \mathrm{L} / \mathrm{min}$ for $1 \mathrm{~min}$ ( $\mathrm{vol} / \mathrm{side}=0.5 \mu \mathrm{L}$ ). As conducted in prior neuropharmacological studies of MA-induced place-conditioning [26,27,71], microinjectors were left in place for an additional $1 \mathrm{~min}$, slowly removed, and sterilized dummy cannulae re-inserted into the guides. Animals then were placed into the place-conditioning chambers for the 15-min test period. The order of U0126 dosing was pseudo-randomly assigned across four consecutive test days, with 1-3 mice per cohort receiving any particular U0126 dose. An additional subset of mice within each of the three experimental cohorts tested under our microinjection procedures $(n=1-3 /$ cohort) were infused only with water vehicle (VEH) to control for the effects of repeated microinjection upon place-preference magnitude. The data from the U0126 study were analyzed using a mixed ANOVA with repeated measures on the Dose factor.

Upon the completion of testing, mice were euthanized and brains drop-fixed in $4 \%$ paraformaldehyde. Brains were sectioned $(50 \mu \mathrm{m})$ along the coronal plane on a vibratome and then stained with Cresyl violet. Sections were then viewed under a light microscope for microinjector placement within the vmPFC. Mice with placements outside the prelim$\mathrm{bic} /$ infralimbic cortices were excluded from the data analyses.

\subsection{Immunoblotting}

Immunoblotting procedures were conducted to determine whether or not individual differences in the magnitude and direction of MA-induced place-conditioning exhibited by B6J mice correlated with ERK activity within the mPFC by examining for total and (Tyr204)ERK phosphorylation (pERK). As described in our published work using these same mice $[26,27,71]$, a subset of CPP, CPA, and Neutral mice from the place-conditioning study ( $n=12-14$ / phenotype) were rapidly decapitated immediately (within $2-5 \mathrm{~min}$ ) upon completion of the post-test and phenotyping. The mPFC was excised over ice and protein content in the samples determined using the BCA method, as described previously (see Figure 1B) [27]. To provide a baseline of ERK expression and phosphorylation, a MA-naïve control group was included in this study that received four saline injection pairings with each compartment of the place-conditioning apparatus and then allowed free-access to both compartments $[26,27,71]$. Immunoblotting procedures for the detection of ERK in $30 \mu \mathrm{g}$ protein samples were performed as described previously $[27,47,57,65]$ and employed a rabbit anti-ERK1/2 primary antibody (Santa Cruz Biotechnology, Santa Cruz, CA, USA; 1:1000 dilution) or a mouse p(Tyr204)ERK1/2 (Santa Cruz Biotechnology, Santa Cruz, CA, USA; 1:1000 dilution). After primary antibody incubation, membranes were washed prior to being incubated with a horseradish peroxidase-conjugated goat anti-rabbit or anti-mouse secondary antibody (Millipore, Burlington, MA, USA; 1:40,000-1:80,000 dilution) for $90 \mathrm{~min}$. Membranes were then washed again, and immunoreactive bands were detected by enhanced chemiluminescence using either ECL Plus (GE Healthcare, Chicago, IL, USA) or Pierce SuperSignal West Femto (Fisher Scientific, Waltham, MA, USA). A rabbit anti-calnexin polyclonal primary antibody (Stressgen) was used to ensure even protein loading ( $30 \mu \mathrm{g} / \mathrm{lane})$ and transfer. Scans of the raw immunoblots employed in this analysis are provided as unpublished material. ImageJ (NIH, Bestheda, MD, USA) was used to quantify the immunoreactivity of each protein. $\mathrm{pERK} /$ total ERK ratios were calculated for each animal, and for group comparisons, values of MA-conditioned animals were expressed as a percentage of average of the saline-injected animals on each gel $(n=3-$ 4). The data were analyzed by ANOVA, followed by LSD post-hoc tests and a Pearson test correlated the ratio of phospho:total ERK with CPP Score ( $\alpha=0.05$ for analyses). 


\section{Conclusions}

The results of the present study provide novel evidence that ERK activation within $\mathrm{mPFC}$ is a biomolecular response to a drug-conditioned context that drives the positive affective effects of MA. While the downstream targets of ERK phosphorylation within the mPFC driving MA-conditioned reward are unknown, mGlu5 appears to be a critical target of ERK-directed signaling regulating MA reinforcement and intake.

Author Contributions: Data curation: E.K.F., S.G.Q., D.M., D.M.F. and K.K.S.; formal analysis: T.E.K. and K.K.S.; funding acquisition: P.F.W. and K.K.S.; investigation: E.K.F. and S.G.Q.; methodology: E.K.F.; project administration: T.E.K. and K.K.S.; resources: P.F.W. and T.E.K.; supervision: K.K.S.; writing-original draft: E.K.F., S.G.Q. and D.M.F.; writing-review and editing: S.G.Q., D.M., P.F.W., T.E.K. and K.K.S. All authors have read and agreed to the published version of the manuscript.

Funding: This work was funded by NIH grants AA016650 (KKS) and DA10309 (PFW) and funds from the Undergraduate Research and Creative Activities program of UCSB (EKF, SGQ, DM, and DMF).

Institutional Review Board Statement: Not applicable.

Informed Consent Statement: Not applicable.

Data Availability Statement: The data presented in this study are available on request from the corresponding author. The data are not publicly available due to formatting constraints.

Conflicts of Interest: The authors declare no conflict of interest.

\section{References}

1. Drug Enforcement Administration. National Drug Threat Assessment; Document No. DEA-DCT-DIR-007-20; Strategic Intelligence Section: Washington, DC, USA, 2019.

2. United Nations Office on Drugs and Crime: World Drug Report 2019; Sales No. E.19.XI.8; United Nations Publication: New York, NY, USA, 2019.

3. Rothman, R.B.; Baumann, M.H. Monoamine transporters and psychostimulant drugs. Eur. J. Pharmacol. 2003, 479, 23-40. [CrossRef] [PubMed]

4. Suzuki, O.; Hattori, H.; Asano, M.; Oya, M.; Katsumata, Y. Inhibition of monoamine oxidase by d-methamphetamine. Biochem. Pharmacol. 1980, 29, 2071-2073. [CrossRef]

5. Sulzer, D.; Sonders, M.S.; Poulsen, N.W.; Galli, A. Mechanisms of neurotransmitter release by amphetamines: A review. Prog. Neurobiol. 2005, 75, 406-433. [CrossRef] [PubMed]

6. Sekine, Y.; Iyo, M.; Ouchi, Y.; Matsunaga, T.; Tsukada, H.; Okada, H.; Yoshikawa, E.; Futatsubashi, M.; Takei, N.; Mori, N. Methamphetamine-related psychiatric symptoms and reduced brain dopamine transporters studied with PET. Am. J. Psychiatry 2001, 158, 1206-1214. [CrossRef] [PubMed]

7. Volkow, N.D.; Chang, L.; Wang, G.J.; Fowler, J.S.; Franceschi, D.; Sedler, M.; Gatley, S.J.; Miller, E.; Hitzemann, R.; Ding, Y.S.; et al. Loss of dopamine transporters in methamphetamine abusers recovers with protracted abstinence. J. Neurosci. 2001, 21, 9414-9418. [CrossRef]

8. Volkow, N.D.; Chang, L.; Wang, G.J.; Fowler, J.S.; Ding, Y.S.; Sedler, M.; Logan, J.; Franceschi, D.; Gatley, J.; Hitzemann, R.; et al. Low level of brain dopamine D2 receptors in methamphetamine abusers: Association with metabolism in the orbitofrontal cortex. Am. J. Psychiatry 2001, 158, 2015-2021. [CrossRef]

9. Johanson, C.E.; Frey, K.A.; Lundahl, L.H.; Keenan, P.; Lockhart, N.; Roll, J.; Galloway, G.P.; Koeppe, R.A.; Kilbourn, M.R.; Robbins, T.; et al. Cognitive function and nigrostriatal markers in abstinent methamphetamine abusers. Psychopharmacology 2006, 185, 327-338. [CrossRef]

10. McCann, U.D.; Ricaurte, G.A. Amphetamine neurotoxicity: Accomplishments and remaining challenges. Neurosci. Biobehav. Rev. 2004, 27, 821-826. [CrossRef]

11. Yamamoto, B.K.; Moszczynska, A.; Gudelsky, G.A. Amphetamine toxicities: Classical and emerging mechanisms. Ann. N. Y. Acad. Sci. 2010, 1187, 101-121. [CrossRef]

12. Steinkellner, T.; Freissmuth, M.; Sitte, H.H.; Montgomery, T. The ugly side of amphetamines: Short- and long-term toxicity of 3,4methylenedioxymethamphetamine (MDMA, 'Ecstasy'), methamphetamine and D-amphetamine. Biol. Chem. 2011, 392, $103-115$. [CrossRef]

13. Phillips, T.J.; Mootz, J.R.; Reed, C. Identification of Treatment Targets in a Genetic Mouse Model of Voluntary Methamphetamine Drinking. Int. Rev. Neurobiol. 2016, 126, 39-85. [CrossRef] [PubMed]

14. Cruickshank, C.C.; Dyer, K.R. A review of the clinical pharmacology of methamphetamine. Addiction 2009, 104, 1085-1099. [CrossRef] [PubMed]

15. Grilly, D.M.; Loveland, A. What is a "low dose" of D-amphetamine for inducing behavioral effects in laboratory rats? Psychopharmacology 2001, 153, 155-169. [CrossRef] [PubMed] 
16. Schuckit, M.A.; Tipp, J.E.; Smith, T.L.; Wiesbeck, G.A.; Kalmijn, J. The relationship between Self-Rating of the Effects of alcohol and alcohol challenge results in ninety-eight young men. J. Stud. Alcohol. 1997, 58, 397-404. [CrossRef]

17. DiFranza, J.R.; Savageau, J.A.; Fletcher, K.; Ockene, J.K.; Rigotti, N.A.; McNeill, A.D.; Coleman, M.; Wood, C. Recollections and repercussions of the first inhaled cigarette. Addict. Behav. 2004, 29, 261-272. [CrossRef]

18. Fergusson, D.M.; Horwood, L.J.; Lynskey, M.T.; Madden, P.A. Early reactions to cannabis predict later dependence. Arch. Gen. Psychiatry 2003, 60, 1033-1039. [CrossRef]

19. Davidson, E.S.; Finch, J.F.; Schenk, S. Variability in subjective responses to cocaine: Initial experiences of college students. Addict. Behav. 1993, 18, 445-453. [CrossRef]

20. Chait, L.D. Factors influencing the reinforcing and subjective effects of d-amphetamine in humans. Behav. Pharmacol. 1993, 4, 191-199. [CrossRef]

21. De Wit, H.; Uhlenhuth, E.H.; Johanson, C.E. Individual differences in the reinforcing and subjective effects of amphetamine and diazepam. Drug Alcohol Depend. 1986, 16, 341-360. [CrossRef]

22. Wheeler, J.M.; Reed, C.; Burkhart-Kasch, S.; Li, N.; Cunningham, C.L.; Janowsky, A.; Franken, F.H.; Wiren, K.M.; Hashimoto, J.G.; Scibelli, A.C.; et al. Genetically correlated effects of selective breeding for high and low methamphetamine consumption. Genes Brain Behav. 2009, 8, 758-771. [CrossRef]

23. Shabani, S.; McKinnon, C.S.; Reed, C.R.; Cunningham, C.L.; Phillips, T.J. Sensitivity to rewarding or aversive effects of methamphetamine determines methamphetamine intake. Genes Brain Behav. 2011, 10, 625-636. [CrossRef] [PubMed]

24. Shabani, S.; Mckinnon, C.S.; Cunningham, C.L.; Phillips, T.J. Profound reduction in sensitivity to the aversive effects of methamphetamine in mice bred for high methamphetamine intake. Neuropharmacology 2012, 62, 1134-1141. [CrossRef] [PubMed]

25. Shabani, S.; Dobbs, L.K.; Ford, M.M.; Mark, G.P.; Finn, D.A.; Phillips, T.J. A genetic animal model of differential sensitivity to methamphetamine reinforcement. Neuropharmacology 2012, 62, 2169-2177. [CrossRef] [PubMed]

26. Szumlinski, K.K.; Lominac, K.D.; Campbell, R.R.; Cohen, M.; Fultz, E.K.; Brown, C.N.; Miller, B.W.; Quadir, S.G.; Martin, D.; Thompson, A.B.; et al. Methamphetamine addiction vulnerability: The glutamate, the bad, and the ugly. Biol. Psychiatry 2017, 81, 959-970. [CrossRef] [PubMed]

27. Lominac, K.D.; Quadir, S.G.; Barrett, H.M.; McKenna, C.L.; Schwartz, L.M.; Ruiz, P.N.; Wroten, M.G.; Campbell, R.R.; Miller, B.W.; Holloway, J.J.; et al. Prefrontal glutamate correlates of methamphetamine sensitization and preference. Eur. J. Neurosci. 2016, 43, 689-702. [CrossRef] [PubMed]

28. Brown, C.N.; Fultz, E.K.; Ferdousian, S.; Rogers, S.; Lustig, E.; Page, A.; Shahin, J.R.; Flaherty, D.M.; Von Jonquieres, G.; Bryant, C.D.; et al. Transgenic Analyses of Homer2 Function Within Nucleus Accumbens Subregions in the Regulation of Methamphetamine Reward and Reinforcement in Mice. Front. Psychiatry 2020, 11, 11. [CrossRef]

29. Lominac, K.D.; Sacramento, A.D.; Szumlinski, K.K.; Kippin, T.E. Distinct neurochemical adaptations within the nucleus accumbens produced by a history of self-administered vs non-contingently administered intravenous methamphetamine. Neuropsychopharmacology 2012, 37, 707-722. [CrossRef]

30. Chesworth, R.; Brown, R.M.; Kim, J.H.; Lawrence, A.J. The metabotropic glutamate 5 receptor modulates extinction and reinstatement of methamphetamine-seeking in mice. PLoS ONE 2013, 8, e68371. [CrossRef]

31. Miyatake, M.; Narita, M.; Shibasak, M.; Nakamura, A.; Suzuki, T. Glutamatergic neurotransmission and protein kinase C play a role in neuron-glia communication during the development of methamphetamine-induced psychological dependence. Eur. $J$. Neurosci. 2005, 22, 1476-1488. [CrossRef]

32. Herrold, A.A.; Voigt, R.M.; Napier, T.C. mGluR5 is necessary for maintenance of methamphetamine-induced associative learning. Eur. Neuropsychopharmacol. 2013, 23, 691-696. [CrossRef]

33. Gass, J.T.; Osborne, M.P.; Watson, N.L.; Brown, J.L.; Olive, M.F. mGluR5 antagonism attenuates methamphetamine reinforcement and prevents reinstatement of methamphetamine-seeking behavior in rats. Neuropsychopharmacology 2009, 34, 820-833. [CrossRef] [PubMed]

34. Osborne, M.P.; Olive, M.F. A role for mGluR5 receptors in intravenous methamphetamine self-administration. Ann. N. Y. Acad. Sci. 2008, 1139, 206-211. [CrossRef] [PubMed]

35. Kufahl, P.R.; Hood, L.E.; Nemirovsky, N.E.; Barabas, P.; Halstengard, C.; Villa, A.; Moore, E.; Watterson, L.R.; Olive, M.F. Positive allosteric modulation of mGluR5 accelerates extinction learning but not relearning following methamphetamine selfadministration. Front. Pharmacol. 2012, 3, 194. [CrossRef] [PubMed]

36. Widholm, J.J.; Gass, J.T.; Cleva, R.M.; Olive, M.F. The mGluR5 positive allosteric modulator CDPPB does not alter extinction or contextual reinstatement of methamphetamine-seeking behavior in rats. J. Addict. Res. Ther. 2011, S1. [CrossRef] [PubMed]

37. Crocker, C.E.; Bernier, D.C.; Hanstock, C.C.; Lakusta, B.; Purdon, S.E.; Seres, P.; Tibbo, P.G. Prefrontal glutamate levels differentiate early phase schizophrenia and methamphetamine addiction: A (1)H MRS study at 3 Tesla. Schizophr. Res. 2014, 157, $231-237$. [CrossRef]

38. Ernst, T.; Chang, L. Adaptation of brain glutamate plus glutamine during abstinence from chronic methamphetamine use. J. Neuroimmune Pharmacol. 2008, 3, 165-172. [CrossRef]

39. O'Neill, J.; Tobias, M.C.; Hudkins, M.; London, E.D. Glutamatergic neurometabolites during early abstinence from chronic methamphetamine abuse. Int. J. Neuropsychopharmacol. 2014, 18. [CrossRef]

40. Zamora-Martinez, E.R.; Edwards, S. Neuronal extracellular signal-regulated kinase (ERK) activity as marker and mediator of alcohol and opioid dependence. Front. Integr. Neurosci. 2014, 8, 24. [CrossRef] 
41. Lu, L.; Koya, E.; Zhai, H.; Hope, B.T.; Shaham, Y. Role of ERK in cocaine addiction. Trends Neurosci. 2006, 29, 695-703. [CrossRef]

42. Sun, W.L.; Quizon, P.M.; Zhu, J. Molecular Mechanism: ERK Signaling, Drug Addiction, and Behavioral Effects. Prog. Mol. Biol. Trans. Sci. 2015, 137, 1-40. [CrossRef]

43. Rosen, L.G.; Sun, N.; Rushlow, W.; Laviolette, S.R. Molecular and neuronal plasticity mechanisms in the amygdala-prefrontal cortical circuit: Implications for opiate addiction memory formation. Front. Neurosci. 2015, 9, 399. [CrossRef] [PubMed]

44. Huang, M.; Yan, C.; Yang, X.; Zhou, X.; Lv, W.; Guo, N.; Li, Y.; Bai, J. Thioredoxin-1 downregulation in the nucleus accumbens promotes methamphetamine-primed reinstatement in mice. Neuropharmacology 2018, 139, 117-123. [CrossRef] [PubMed]

45. Wen, D.; Hui, R.; Liu, Y.; Luo, Y.; Wang, J.; Shen, X.; Xie, B.; Yu, F.; Cong, B.; Ma, C. Molecular hydrogen attenuates methamphetamine-induced behavioral sensitization and activation of ERK- $\Delta$ FosB signaling in the mouse nucleus accumbens. Prog. Neuropsychopharmacol. Biol. Psychiatry 2020, 97, 109781. [CrossRef] [PubMed]

46. Park, J.M.; Hu, J.H.; Milshteyn, A.; Zhang, P.W.; Moore, C.G.; Park, S.; Datko, M.C.; Domingo, R.D.; Reyes, C.M.; Wang, X.J.; et al. A prolyl-isomerase mediates dopamine-dependent plasticity and cocaine motor sensitization. Cell 2013, 154, 637-650. [CrossRef] [PubMed]

47. Campbell, R.R.; Domingo, R.D.; Williams, A.R.; Wroten, M.G.; McGregor, H.A.; Waltermire, R.S.; Greentree, D.I.; Goulding, S.P.; Thompson, A.B.; Lee, K.M.; et al. Increased Alcohol-Drinking Induced by Manipulations of mGlu5 Phosphorylation within the Bed Nucleus of the Stria Terminalis. J. Neurosci. 2019, 39, 2745-2761. [CrossRef]

48. Ruan, Q.T.; Yazdani, N.; Blum, B.C.; Beierle, J.A.; Lin, W.; Coelho, M.A.; Fultz, E.K.; Healy, A.F.; Shahin, J.R.; Kandola, A.K.; et al. A Mutation in Hnrnph1 That Decreases Methamphetamine-Induced Reinforcement, Reward, and Dopamine Release and Increases Synaptosomal hnRNP H and Mitochondrial Proteins. J. Neurosci. 2020, 40, 107-130. [CrossRef]

49. Fultz, E.K.; Martin, D.L.; Hudson, C.N.; Kippin, T.E.; Szumlinski, K.K. Methamphetamine-alcohol interactions in murine models of sequential and simultaneous oral drug-taking. Drug Alcohol Depend. 2017, 177, 178-186. [CrossRef]

50. Shab, G.; Fultz, E.K.; Page, A.; Coelho, M.A.; Brewin, L.W.; Stailey, N.; Brown, C.N.; Bryant, C.D.; Kippin, T.E.; Szumlinski, K.K. The motivational valence of methamphetamine relates inversely to subsequent methamphetamine self-administration in female C57BL/6J mice. Behav. Brain Res. 2021, 398, 112959. [CrossRef]

51. Mizoguchi, H.; Yamada, K.; Mizuno, M.; Mizuno, T.; Nitta, A.; Noda, Y.; Nabeshima, T. Regulations of methamphetamine reward by extracellular signal-regulated kinase $1 / 2$ / ets-like gene-1 signaling pathway via the activation of dopamine receptors. Mol. Pharmacol. 2004, 65, 1293-1301. [CrossRef]

52. McDaid, J.; Graham, M.P.; Napier, T.C. Methamphetamine-induced sensitization differentially alters pCREB and DeltaFosB throughout the limbic circuit of the mammalian brain. Mol. Pharmacol. 2006, 70, 2064-2074. [CrossRef]

53. Su, H.; Sun, T.; Wang, X.; Du, Y.; Zhao, N.; Zhu, J.; Yan, J.; Chen, T.; Yun, K. Levo-tetrahydropalmatine attenuates methamphetamine reward behavior and the accompanying activation of ERK phosphorylation in mice. Neurosci. Lett. 2020, 714, 134416. [CrossRef] [PubMed]

54. Huang, S.; Dai, Y.; Zhang, C.; Yang, C.; Huang, Q.; Hao, W.; Shen, H. Higher impulsivity and lower grey matter volume in the bilateral prefrontal cortex in long-term abstinent individuals with severe methamphetamine use disorder. Drug Alcohol Depend. 2020, 212, 108040. [CrossRef]

55. Malcolm, R.; Myrick, H.; Li, X.; Henderson, S.; Brady, K.T.; George, M.S.; See, R.E. Regional Brain Activity in Abstinent Methamphetamine Dependent Males Following Cue Exposure. J. Drug Abuse 2016, 2, 16. [CrossRef] [PubMed]

56. London, E.D.; Simon, S.L.; Berman, S.M.; Mandelkern, M.A.; Lichtman, A.M.; Bramen, J.; Shinn, A.K.; Miotto, K.; Learn, J.; Dong, Y.; et al. Mood disturbances and regional cerebral metabolic abnormalities in recently abstinent methamphetamine abusers. Arch. Gen. Psychiatry 2004, 61, 73-84. [CrossRef]

57. Rubinfeld, H.; Seger, R. The ERK cascade: A prototype of MAPK signaling. Mol. Biotechnol. 2005, 31, 151-174. [CrossRef]

58. Salzmann, J.; Marie-Claire, C.; Le Guen, S.; Roques, B.P.; Noble, F. Importance of ERK activation in behavioral and biochemical effects induced by MDMA in mice. Br. J. Pharmacol. 2003, 140, 831-838. [CrossRef] [PubMed]

59. Valjent, E.; Corvol, J.C.; Pages, C.; Besson, M.J.; Maldonado, R.; Caboche, J. Involvement of the extracellular signal-regulated kinase cascade for cocaine-rewarding properties. J. Neurosci. 2000, 20, 8701-8709. [CrossRef]

60. Valjent, E.; Caboche, J.; Vanhoutte, P. Mitogen-activated protein kinase/extracellular signal-regulated kinase induced gene regulation in brain: A molecular substrate for learning and memory? Mol. Neurobiol. 2001, 23, 83-99. [CrossRef]

61. Valjent, E.; Corvol, J.C.; Trzaskos, J.M.; Girault, J.A.; Hervé, D. Role of the ERK pathway in psychostimulant-induced locomotor sensitization. BMC Neurosci. 2006, 7, 20. [CrossRef]

62. Valjent, E.; Bertran-Gonzalez, J.; Hervé, D.; Fisone, G.; Girault, J.A. Looking BAC at striatal signaling: Cell-specific analysis in new transgenic mice. Trends Neurosci. 2009, 32, 538-547. [CrossRef]

63. Gerdjikov, T.V.; Ross, G.M.; Beninger, R.J. Place preference induced by nucleus accumbens amphetamine is impaired by antagonists of ERK or p38 MAP kinases in rats. Behav. Neurosci. 2004, 118, 740-750. [CrossRef] [PubMed]

64. Son, J.S.; Jeong, Y.C.; Kwon, Y.B. Regulatory effect of bee venom on methamphetamine-induced cellular activities in prefrontal cortex and nucleus accumbens in mice. Biol. Pharm. Bull. 2015, 38, 48-52. [CrossRef] [PubMed]

65. Fultz, E.K.; Szumlinski, K.K. Prior binge-drinking history promotes the positive affective valence of methamphetamine in mice. Drug Alcohol Depend. 2018, 183, 150-154. [CrossRef] [PubMed]

66. Sern, K.R.; Fultz, E.K.; Coelho, M.A.; Bryant, C.D.; Szumlinski, K.K. A prior history of binge-drinking increases sensitivity to the motivational valence of methamphetamine in female C57BL/6J mice. Subst. Abuse 2020, 14. [CrossRef] [PubMed] 
67. Penzner, J.H.; Thompson, D.L.; Arth, C.; Fowler, J.K.; Ary, A.W.; Szumlinski, K.K. Protracted 'anti-addictive' effects of adolescent phenylpropanolamine exposure in C57BL/6J mice. Addict. Biol. 2008, 13, 310-325. [CrossRef] [PubMed]

68. Reed, C.; Stafford, A.M.; Mootz, J.R.K.; Baba, H.; Erk, J.; Phillips, T.J. A breeding strategy to identify modifiers of high genetic risk for methamphetamine intake. Genes Brain Behav. 2020, 18, e12667. [CrossRef]

69. Harkness, J.H.; Shi, X.; Janowsky, A.; Phillips, T.J. Trace Amine-Associated Receptor 1 Regulation of Methamphetamine Intake and Related Traits. Neuropsychopharmacology 2015, 40, 2175-2184. [CrossRef]

70. Hu, J.H.; Yang, L.; Kammermeier, P.J.; Moore, C.G.; Brakeman, P.R.; Tu, J.; Yu, S.; Petralia, R.S.; Li, Z.; Zhang, P.W.; et al. Preso1 dynamically regulates group I metabotropic glutamate receptors. Nat. Neurosci. 2012, 15, 836-844. [CrossRef]

71. Lominac, K.D.; McKenna, C.L.; Schwartz, L.M.; Ruiz, P.N.; Wroten, M.G.; Miller, B.W.; Holloway, J.J.; Travis, K.O.; Rajasekar, G.; Maliniak, D.; et al. Mesocorticolimbic monoamine correlates of methamphetamine sensitization and motivation. Front. Syst. Neurosci. 2014, 8, 70. [CrossRef]

72. Lominac, K.D.; Oleson, E.B.; Pava, M.; Klugmann, M.; Schwarz, M.K.; Seeburg, P.H.; During, M.J.; Worley, P.F.; Kalivas, P.W.; Szumlinski, K.K. Distinct roles for different Homer1 isoforms in behaviors and associated prefrontal cortex function. J. Neurosci. 2005, 25, 11586-11594. [CrossRef]

73. Ary, A.W.; Lominac, K.D.; Wroten, M.G.; Williams, A.R.; Campbell, R.R.; Ben-Shahar, O.; von Jonquieres, G.; Klugmann, M.; Szumlinski, K.K. Imbalances in prefrontal cortex CC-Homer1 versus CC-Homer2 expression promote cocaine preference. J. Neurosci. 2013, 33, 8101-8113. [CrossRef] [PubMed]

74. Favata, M.F.; Horiuchi, K.Y.; Manos, E.J.; Daulerio, A.J.; Stradley, D.A.; Feeser, W.S.; Van Dyk, D.E.; Pitts, W.J.; Earl, R.A.; Hobbs, F.; et al. Identification of a novel inhibitor of mitogen-activated protein kinase kinase. J. Biol. Chem. 1998, 273, 18623-18632. [CrossRef] [PubMed] 